\title{
Erratum to: Modeling the Effect of Carburization and Quenching on the Development of Residual Stresses and Bending Fatigue Resistance of Steel Gears
}

\author{
Zhichao Li, Andrew M. Freborg, Bruce D. Hansen, and T.S. Srivatsan
}

\section{Erratum to: J. of Materi Eng and Perform}

DOI 10.1007/s11665-012-0306-0

The caption for Fig. 10 should read as follows:

Stress distributions from the dynamic contact analyses. (a) With heat-treatment residual stresses and (b) without heattreatment residual stresses in one tooth.

The online version of the original article can be found under doi: 10.1007/s11665-012-0306-0.

Zhichao Li, and Andrew M. Freborg, Deformation Control Technology, Inc, 7261 Engle Road, Suite 105, Cleveland, OH 44130; Bruce D. Hansen, Sikorsky Aircraft Corporation, 6900 Main Street, Stratford, CT 06615; and T.S. Srivatsan, Division of Materials Science and Engineering, Department of Mechanical Engineering, The University of Akron, Akron, OH 44325. Contact e-mails: zli@ DeformationControl.com, Andy.freborg@deformationcontrol.com, bruce.hansen@sikorsky.com, and tsrivatsan@uakron.edu. 